\title{
Multicopy targets for Plasmodium vivax and Plasmodium falciparum detection by colorimetric LAMP
}

Oscar Nolasco ${ }^{1,3^{*} \mathbb{C} \text {, Jhoel Montoya }}{ }^{2}$, Ana L. Rosales Rosas ${ }^{3}$, Scarlett Barrientos ${ }^{3}$, Anna Rosanas-Urgell ${ }^{4}$ and Dionicia Gamboa $1,3,5$

\begin{abstract}
Background: Loop-mediated isothermal amplification (LAMP) for malaria diagnosis at the point of care (POC) depends on the detection capacity of synthesized nucleic acids and the specificity of the amplification target. To improve malaria diagnosis, new colorimetric LAMP tests were developed using multicopy targets for Plasmodium vivax and Plasmodium falciparum detection.
\end{abstract}

Methods: The cytochrome oxidase I (COX1) mitochondrial gene and the non-coding sequence Pvr47 for P. vivax, and the sub-telomeric sequence of erythrocyte membrane protein 1 (EMP1) and the non-coding sequence Pfr364 for $P$. falciparum were targeted to design new LAMP primers. The limit of detection (LOD) of each colorimetric LAMP was established and assessed with DNA extracted by mini spin column kit and the Boil \& Spin method from 28 microscopy infections, 101 malaria submicroscopic infections detected by real-time PCR only, and 183 negatives infections by both microscopy and PCR.

Results: The LODs for the colorimetric LAMPs were estimated between 2.4 to 3.7 parasites/ $\mu \mathrm{L}$ of whole blood. For P. vivax detection, the colorimetric LAMP using the COX1 target showed a better performance than the Pvr 47 target, whereas the Pfr364 target was the most specific for P. falciparum detection. All microscopic infections of $P$. vivax were detected by PVCOX1-LAMP using the mini spin column kit DNA extraction method and 81\% (17/21) were detected using Boil \& Spin sample preparation. Moreover, all microscopic infections of P. falciparum were detected by Pfr364LAMP using both sample preparation methods. In total, PvCOX1-LAMP and Pfr364-LAMP detected 80.2\% (81 samples) of the submicroscopic infections using the DNA extraction method by mini spin column kit, while 36.6\% (37 samples) were detected using the Boil \& Spin sample preparation method.

Conclusion: The colorimetric LAMPs with multicopy targets using the COX1 target for $P$. vivax and the Pfr364 for $P$. falciparum have a high potential to improve POC malaria diagnosis detecting a greater number of submicroscopic Plasmodium infections.

Keywords: Malaria, Molecular diagnosis, Colorimetric LAMP, Pfr364, PVr47, Cox1, PfEMP1

*Correspondence: oscar.nolasco.c@upch.pe

1 Instituto de Medicina Tropical "Alexander von Humboldt" Universidad Peruana Cayetano Heredia, Lima, Peru

Full list of author information is available at the end of the article

\section{Background}

Although significant progress has been achieved in malaria control and elimination over the last few decades, malaria remains a major public health problem, with 229 million cases worldwide in 2019 [1]. In Peru, 15,721 malaria cases were reported in 2020 [2], showing

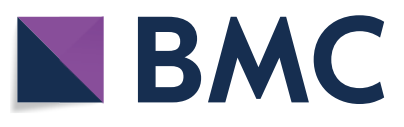

(c) The Author(s) 2021. This article is licensed under a Creative Commons Attribution 4.0 International License, which permits use, sharing, adaptation, distribution and reproduction in any medium or format, as long as you give appropriate credit to the original author(s) and the source, provide a link to the Creative Commons licence, and indicate if changes were made. The images or other third party material in this article are included in the article's Creative Commons licence, unless indicated otherwise in a credit line to the material. If material is not included in the article's Creative Commons licence and your intended use is not permitted by statutory regulation or exceeds the permitted use, you will need to obtain permission directly from the copyright holder. To view a copy of this licence, visit http://creativeco mmons.org/licenses/by/4.0/. The Creative Commons Public Domain Dedication waiver (http://creativecommons.org/publicdomain/ zero/1.0/) applies to the data made available in this article, unless otherwise stated in a credit line to the data. 
marked active transmission in rural and remote areas with poor access to medical care, despite the effort of the Peruvian malaria control programme (i.e., Plan Malaria Cero, PMC) to provide field-diagnosis based on microscopy detection and treatment to a large part of the affected population.

According to surveillance reports based on passive case detection and microscopy diagnosis, Plasmodium vivax causes four times more malaria infections than Plasmodium falciparum in the Peruvian Amazon region. However, such reports are based on passive case detection and microscopy assessment, which miss a high proportion of asymptomatic and submicroscopic infections that are only detected by molecular diagnosis $[3,4]$. Infections that escape current malaria surveillance do not receive treatment and thus contribute to the maintenance of malaria transmission in communities [3].

Species-specific diagnosis is critical for adequate treatment in areas where both of the aforementioned species co-exist. In Peru, P. falciparum infections are treated using artemisinin-based combination therapy (ACT) with mefloquine and primaquine as partner drug, whereas $P$. vivax treatment is based on chloroquine to clear blood stages and primaquine to eliminate dormant liver stages (i.e., hypnozoites) that cause relapse [5].

Currently, the gold standard of malaria diagnosis in the field is still based on thin and thick blood smear and microscopy examination. In rural and remote areas, the major challenges that might lead to misdiagnoses are the lack of good diagnostic facilities, untrained microscopists, and the predominance of infections with parasitemia levels lower than 100 parasites/ $\mu \mathrm{L}[6,7]$. In contexts where reliable microscopy is not available, diagnosis is done using rapid diagnostics tests (RDTs) based on monoclonal or polyclonal antibodies that detect malaria-specific antigens with a sensitivity comparable to microscopy [8]. However, several of these cannot detect low-density infections of $P$. vivax [9] or HRP2-negative $P$ falciparum infections, which are reported in large proportions in Peru [10, 11].

PCR-based molecular diagnosis has shown better performance in detecting submicroscopic and asymptomatic infections in several studies carried out in Peru [12-15]. The majority of such studies have used PCR based on $18 \mathrm{~S}$ $r R N A$ detection, which exists as four to eight copies in the $P$. vivax genome and five to eight copies in P. falciparum [16].

Despite the greater sensitivity of PCR-based techniques, their use at point of care (POC) is still challenging due to the dependence on expensive laboratory equipment and health workers' technical capacity. On the other hand, molecular techniques based on isothermal amplification, such as loop-mediated isothermal amplification (LAMP), have the potential for the field diagnosis of malaria. LAMP allows for DNA amplification under isothermal conditions [17], and the results of the synthesis product can be detected visually by turbidity, change in colour reaction, or fluorescence $[18,19]$.

LAMP assays have been developed and evaluated to detect different Plasmodium species that cause human disease, and many of them with a limit of detection between 1 to 5 parasites $/ \mu \mathrm{L}$ depending on the genomic target [20-30]. The majority of LAMPs use $18 \mathrm{~S}$ rRNA and mitochondrial targets to detect pan genus Plasmodium or P. falciparum species. Most LAMP studies have been carried out in the Asian regions, with very few in South America [31, 32].

There are two commercial LAMP platforms that include a simplified system of sample preparation from blood and additional readout equipment, which improves its use as a point of care: the Loopamp MALARIA kits (Eiken Chemical Co. Ltd., Tokyo, Japan) for pan genus Plasmodium, P. falciparum, and P. vivax species detection [22]; and the Illumigene/Alethia Malaria LAMP (Meridian Bioscience, Inc., Cincinnati, OH, USA) [26] for pan genus Plasmodium detection. However, these kits are not routinely used due to their high cost and other operational challenges, such as lengthy sample preparation protocol.

In Peru, the commercial Loopamp ${ }^{\mathrm{TM}}$ MALARIA Pf detection and the Loopamp ${ }^{\mathrm{TM}}$ MALARIA Pv detection were evaluated in two different studies and showed a high operational capacity [33, 34]. Both studies were carried out without the reading equipment and showed crossed reactions in the species-specific identification. The cross-reaction of Loopamp ${ }^{\text {TM }}$ MALARIA Pf detection kit showed a positive reaction in $3.9 \%(8 / 205)$ of $P$. vivax samples detected by PCR [33], and likewise, the Loopamp $^{\mathrm{TM}}$ MALARIA Pv detection kit showed a positive reaction in $7.22 \%(13 / 180)$ of the $P$. falciparum samples detected by PCR [34].

A recent study in Peru evaluated a malachite green colorimetric LAMP (MG-LAMP) versus a fluorescence LAMP (RealAmp) using samples from symptomatic patients. Both LAMPs had problems detecting low parasitemia and mixed infections, specifically detecting $P$. vivax infection [32]. Hence, there is a need to assess alternatives targets in the LAMP assays. The best approach may be to use multicopy targets with genes with high copy number to improve sensitivity and detect low-density and mixed parasite infections $[35,36]$. Recently, the P. vivax Pvr47 gene and P. falciparum Pfr364 gene (with 14 and 41 gene copies respectively) [37], were used in a real-time PCR assay and showed promise for identifying low-density $P$. vivax and P. falciparum infections and mixed infections, despite a variable ratio of species [38]. 
Erythrocyte membrane protein 1 (EMP1), present as several copies in the $P$. falciparum genome, has also been used in PCR and exhibits seven-fold higher sensitivity than the $18 \mathrm{~S}$ ribosomal target [39]. Another very useful PCR target is the mitochondrial cytochrome oxidase 1 (COX1) [14]. In this study, we evaluated multicopy targets in P. vivax (Pvr47 and COX1) and P. falciparum (Pfr364 and EMP1) to improve diagnosis at POC. The targets were assessed by Colorimetric LAMP format using neutral red, $\mathrm{pH}$-sensitive dye for the enhanced visual detection of the amplification product based on a rapid, distinct, and robust colour change from yellow to fuchsia due to the $\mathrm{pH}$ drop by the DNA target amplification. The performance of the method was evaluated using two different sample preparation protocols: the mini spin column kit (E.Z.N.A. ${ }^{\circledR}$ Blood DNA Mini Kit) and the Boil \& Spin method.

\section{Methods}

\section{Primer LAMP design}

First, we explored conserved regions of $P v C O X 1, P v r 47$, Pfr364, and PfEMP1 by aligning sequences available from PlasmoDB (plasmoDB.org) and the NIH genetic sequence database GenBank (https://www.ncbi.nlm. nih.gov/genbank/). Pvr47 and Pfr364 sequences were obtained from Demas et al. [37], composed of 14 Pvr47 copies (P. vivax Sal-I strain) and 41 copies of Pfr364 (subfamilies 1 and 2 of $P$. falciparum 3D7 strain). For the $C O X 1$ and EMP1 genes, we used the complete sequences reported in GenBank.

The LAMP primers were designed using the free software Primer Explorer V5 (http://primerexplorer.jp/lampv 5e/index.html) and were located in a conserved region of each target. Only the primers for the COX1 target were designed by checking manually the main point of primer design described in EIKEN GENOME SITE (http://loopa mp.eiken.co.jp/e/lamp/primer.html). Primer specificity was tested using the NCBI Basic Local Alignment Tool (BLAST) tool https://www.ncbi.nlm.nih.gov/tools/ primer-blast/) and potential secondary structures were analysed with OlygoAnalizer 3.1 (https://www.idtdna. $\mathrm{com} /$ calc/analyzer). Finally, four pairs of primers for each target were selected for LAMP assays (Table 1).

\section{LAMP isothermal conditions}

The colorimetric LAMP assays were optimized to provide a clear visual detection based on the drop in $\mathrm{pH}$ caused by DNA target synthesis. When using the neutral red dye, the $\mathrm{pH}$ drop produces a change in the colour solution from yellow to fuchsia. For this, the reaction mixtures were prepared at a final volume of $25 \mu \mathrm{L}$, containing $0.5 \times$ Bst DNA polymerase reaction buffer $(10 \mathrm{mM}$ Tris$\mathrm{HCl}, 5 \mathrm{mM}\left(\mathrm{NH}_{4}\right)_{2} \mathrm{SO}_{4}, 25 \mathrm{mM} \mathrm{KCl}, 1 \mathrm{mM} \mathrm{MgSO}, 0.05 \%$ Tween 20, pH 8.8 New England Biolabs Inc., MA, USA), $0.2 \mu \mathrm{M}$ each external primer F3 and B3, $2 \mu \mathrm{M}$ each inner primer FIP and BIP, 12U Bstv2.0 DNA polymerase (New England Biolabs Inc., MA, USA), $1.4 \mathrm{mM}$ of each dNTPs, $0.003 \%$ of neutral red dye and $5 \mu \mathrm{L}$ of a test sample. The reaction mixture for the Pvr47-LAMP was adjusted to $6 \mathrm{mM} \mathrm{MgSO}_{4}$, the PvCOX1-LAMP was adjusted to $6 \mathrm{mM} \mathrm{MgSO}_{4}$ and 0.4 $\mathrm{M}$ betaine, the Pfr364-LAMP was adjusted to $8 \mathrm{mM} \mathrm{MgSO}_{4}$ and the PfEMP1-LAMP was adjusted to $8 \mathrm{mM} \mathrm{MgSO}_{4}$ and $0.4 \mathrm{M}$ betaine.

Table 1 Sequences of primers designed for P. vivax and P. falciparum

\begin{tabular}{|c|c|c|c|c|}
\hline Specie & LAMP & Target & & Primers Sequence $\left(5^{\prime} \rightarrow 3^{\prime}\right)$ \\
\hline \multirow[t]{8}{*}{ P. vivax } & PVCOX1-LAMP & $\operatorname{COX} 1$ & F3 & GAATAATTGCACAAGAAAATGTTAAC \\
\hline & & & B3 & GCAACAGGAGATAAAGACATAAGTGA \\
\hline & & & FIP & CAAGTTCTGGAGAACCACATAAAATTG- CCAGGATTATTTGGAGGATTCG \\
\hline & & & BIP & GTCATTTTATCTACAGCAGCAGAATTT- TGGTGGATATAAAGTCCATCCAGT \\
\hline & Pvr47-LAMP & Pvr47 & F3 & AACACCTCCCACCAATCA \\
\hline & & & B3 & GTGAATTATCGAAGGCATAA \\
\hline & & & FIP & TACGCGGAAAATCAGAACAATTCAT- GTGCCAATTTTTTTTTGCGG \\
\hline & & & BIP & ATCTTTCGCTTATCCATTCATCGA-TAGTGACAAAACATAAACACAGC \\
\hline \multirow[t]{8}{*}{ P. falciparum } & PfEMP1-LAMP & EMP1 & F3 & CCGACAAAACTTTCACCCAA \\
\hline & & & B3 & CTGTTGTGTTGTTACCACTAGG \\
\hline & & & FIP & GGTGTAACCACTATCAGTTCCACTA- AGTGGTAAATACAGAGGCAAAC \\
\hline & & & BIP & TCCGAAAGTGAGTATGAAGAATTGG- ATGTTTTATATTTAGGACTACCTGG \\
\hline & Pfr364-LAMP & Pfr364 & F3 & CACTAGGTACGCCAACAT \\
\hline & & & B3 & ACCCACAATTTTGATTGAGATG \\
\hline & & & FIP & GTAGACACCATATGGTACCACGTA- GGATGTGTCTATCATATAGTCCG \\
\hline & & & BIP & TTGTACCCAATTTTCCCCTAGCA- GTGTGTGCAACATCATAATCATCA \\
\hline
\end{tabular}


A positive reaction was assessed by visual inspection and considered as such only if the reaction turned from yellow to fuchsia after $65 \mathrm{~min}$ of incubation at $60{ }^{\circ} \mathrm{C}$. Incubation steps were performed on a Bio-Rad T100 TM Thermal Cycler. (Bio-Rad Laboratories, CA, USA).

\section{Plasmid construction}

To analyse the LOD of each colorimetric LAMPs in target copies, plasmids for each target were assembled through PCR amplification using the external primer F3/ B3. The amplicons were cloned using a TOPO TA cloning kit (Life Technologies). Recombinant plasmid DNA was purified using a Qiagen plasmid mini kit, and the concentration of the extracted plasmid was determined using a Qubit dsDNA BR Assay Kit (ThermoFisher Scientific).

\section{Limit of detection}

The LOD was assessed in two formats: (1) LOD in terms of number of copies per $\mu \mathrm{L}$, for which serial dilutions of each recombinant plasmid with the specific target segment were used; and (2) LOD in terms of number of parasites per $\mu \mathrm{L}$, for which serial dilutions of a cultured sample of $P$. falciparum 3D7 and pooled samples of whole blood from patients infected with $P$. vivax (quantified previously by microscopy and qPCR) were used. Each dilution series was tested 15 times by each colorimetric LAMP. The LOD was calculated using Probit regression whit the MedCalc Statistical Software version 19.2.6 (MedCalc Software bv, Ostend, Belgium; https://www. medcalc.org; 2020).

\section{Reference samples}

The reference samples from the $P$. falciparum 3D7 culture and a pool of blood samples infected with $P$. vivax (microscopy and PCR-confirmed) were supplied by the malaria laboratory at the Universidad Peruana Cayetano Heredia (UPCH). DNA controls were supplied by the Centers for Disease Control and Prevention (CDC). The quality control distribution 4260 of WHO and UK National External Quality Assessment Service (UK NEQAS) Parasitology were used for validation of genus and species. The 4260 material contained five samples: specimen 4307 (Plasmodium ovale 200,000 parasites/ $\mathrm{mL}$ ), specimen 4308 (Plasmodium vivax 20,000 parasites/mL), specimen 4309 (P. falciparum 20,000 parasites/mL), specimen 4310 (No Plasmodium nucleic acid detected), and specimen 4311 (Plasmodium knowlesi 200,000 parasites/mL).

\section{Clinical samples}

A total of 312 blood samples were selected from the sample bank of the Malaria Laboratory at UPCH. The samples were collected from 10 communities (Quistococha,
Santo Tomas, Rumococha, Gamitanacocha, Libertad, 1 de Enero, Salvador, Lago Yuracyacu, Puerto Alegre, and Urcomiraño) from Loreto (Peru) during an active sample collection in 2018. All samples were collected after an informed consent form was signed according to the ethical clearance from the Ethics Review Board of the UPCH, Lima, Peru (SIDISI code 101645).

These samples were categorized into three groups. The first group included 28 samples with infections detected by both microscopy and real-time PCR with $21 P$. vivax infections and 7 P. falciparum infections. All samples showed asexual parasitaemia with more than 100 parasites/ $\mu \mathrm{L}$ as assessed by microscopy, with the exception of three $P$. vivax infections that had $<100$ parasites $/ \mu \mathrm{L}$. The second group included 101 submicroscopic infections (83 P. vivax and 18 P. falciparum infections) detected only by real-time PCR as described by Mangold et al. [40]. The third group included 183 negative samples as determined by both microscopy and real-time PCR; this group of samples was included to assess interference of human DNA with the LAMP primers. Figure 1 shows the flowchart of the experimental procedure and details of the diagnosis of clinical samples are available in Additional file 1 .

\section{Microscopy data}

All the selected samples have a result of the thick drop and thin film for malaria diagnosis. Parasite densities were quantified by counting asexual parasites and gametocytes separately with the number of thick drop leukocytes based on an estimated mean count of 8000 leukocytes per microliter of blood. The counting criteria were applied according to the Peruvian Minister of Health [5] and were carried out with the following formula:

$$
\frac{\mathrm{N}^{\circ} \text { Parasites }}{\mathrm{N}^{\circ} \text { Leukocytes }} \times 8000=\text { Parasites } / \mu \mathrm{L}
$$

\section{DNA extraction by mini spin column}

The DNA was extracted using the EZNA ${ }^{\circledR}$ Blood DNA (Omega Bio-tek, Norcross, GA, USA), following the manufacture's protocol. In brief, $40 \mu \mathrm{L}$ blood was transferred to a sterile microcentrifuge tube adding $250 \mu \mathrm{L} 2 \mathrm{X}$ TEN buffer pH 8.0 (0.2 M NaCl, $0.02 \mathrm{M}$ Tris- $\mathrm{HCl}$ pH 8.0, $0.002 \mathrm{M}$ EDTA pH 8.0), $180 \mu \mathrm{L}$ distilled water, $50 \mu \mathrm{L}$ of $10 \%$ SDS; and $25 \mu \mathrm{L} \mathrm{OB}$ protease solution. The mix was incubated at $65{ }^{\circ} \mathrm{C}$ for $60 \mathrm{~min}$ and centrifuged at $13,000 \mathrm{~g}$ for $5 \mathrm{~min}$; the supernatant was transfer to a new tube, adding $250 \mu \mathrm{L}$ of $\mathrm{BL}$ buffer and $260 \mu \mathrm{L}$ of $100 \%$ ethanol. Then, $500 \mu \mathrm{L}$ of this homogenate was transferred to a mini HiBind ${ }^{\circledR}$ DNA column inserted into a $2 \mathrm{~mL}$ collecting tube and centrifuged at $10,000 \mathrm{~g}$ for $1 \mathrm{~min}$. The 


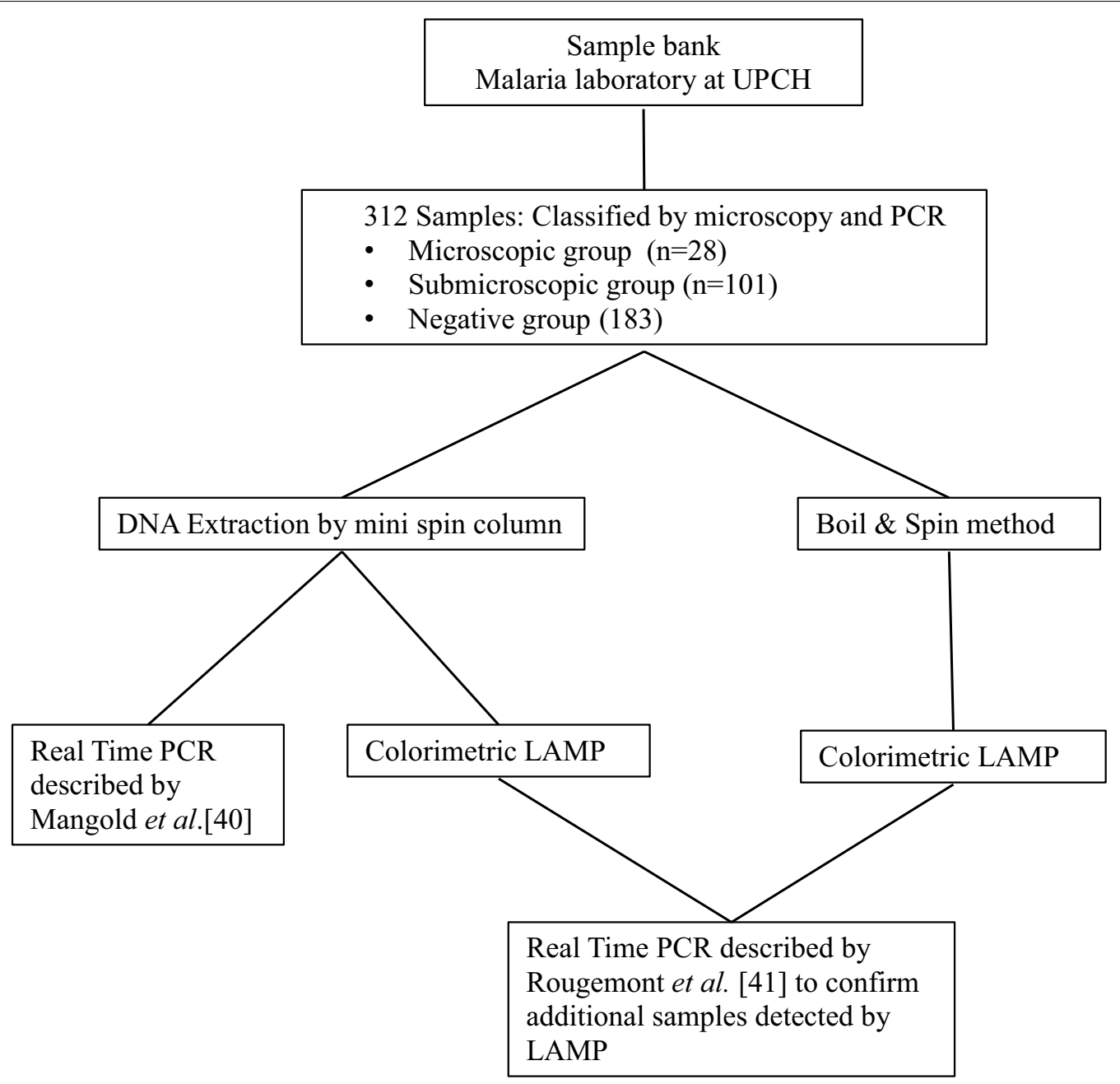

Fig. 1 Flowchart of the experimental procedure

filtrate was discarded, and the mini column was inserted into a new $2 \mathrm{~mL}$ collection tube, $500 \mu \mathrm{L}$ of $\mathrm{HBC}$ buffer was added, then centrifuged at $10,000 \mathrm{~g}$ for $1 \mathrm{~min}$ and the filtrate was discarded. Then, $700 \mu \mathrm{L}$ of wash buffer was added to the column and centrifuged at $10,000 \mathrm{~g}$ for $1 \mathrm{~min}$; this process was repeated once more. The empty HiBind mini DNA column was centrifuged at maximum speed for 2 min to dry the column matrix. The DNA from the column was eluted in $60 \mu \mathrm{L}$ elution buffer preheated to $65{ }^{\circ} \mathrm{C}$. Eluted DNA was stored at $-20{ }^{\circ} \mathrm{C}$. Hereafter, the DNA extracted using this method is referred to as MSC DNA.

\section{Sample preparation using the boiling \& spin extraction method}

The Boil \& Spin method was performed using $40 \mu \mathrm{L}$ $2 \mathrm{X}$ lysis buffer $(8 \mathrm{mM}$ Tris, $80 \mathrm{mM} \mathrm{NaCl}, 0.08 \%$ SDS, $\mathrm{pH} 8.5)$ and $40 \mu \mathrm{L}$ the blood sample. The mixture was homogenized and incubated in a water bath at $95{ }^{\circ} \mathrm{C}$ for $7 \mathrm{~min}$. Next, the homogenate was centrifuged at $13,000 \mathrm{~g}$ for $7 \mathrm{~min}$. Finally, the supernatant was recovered and used for the LAMP analysis. Hereafter, the DNA extracted using this method is referred to as BS DNA.

\section{Species-specific detection by real-time PCR}

The 18S rRNA gene was chosen for species-specific detection using the qPCR performed by Mangold et al. [40]. The reaction mixtures were prepared at a final volume of $25 \mu \mathrm{L}$ with a final concentration of $1 \mathrm{X}$ master mix of PerfeCTa SYBR ${ }^{\circledR}$ Green Fastmix, and $0.3 \mu \mathrm{M}$ each primer PL1473F18 5'-TAACGAACGAGATCTTAA-3' and PL1679R18 5'-GTTCCTCTAAGAAGCTTT-3' [40].

The PCR conditions consisted of an initial denaturation step at $95{ }^{\circ} \mathrm{C}$ for $2 \mathrm{~min}$, followed by 45 cycles of $20 \mathrm{~s}$ at $95{ }^{\circ} \mathrm{C}, 20 \mathrm{~s}$ at $50{ }^{\circ} \mathrm{C}$, and $20 \mathrm{~s}$ at $68{ }^{\circ} \mathrm{C}$, with fluorescence acquisition at the end of each extension step. 
Amplification was immediately followed by a melting curve program consisting of $2 \mathrm{~min}$ at $68^{\circ} \mathrm{C}$, and a stepwise temperature increase of $0.5{ }^{\circ} \mathrm{C} / \mathrm{s}$ until $90{ }^{\circ} \mathrm{C}$, with fluorescence acquisition at each temperature transition. All of the samples with a quantification cycle $(\mathrm{Cq})$ of less than 36.2 were considered positive according to the LOD determined using a serial dilution of the 1st WHO International Standard for Plasmodium falciparum DNA Nucleic Acid Amplification Techniques (NIBSC code 04/176) available at the malaria laboratory, and the same LOD for $P$. vivax was assumed, considering that it is the same amplification target. The melting curve analysis was used to determine the species-specific: a melting peak of $73.5^{\circ} \mathrm{C} \pm 0.5$ was considered to define $P$. falciparum infection and a peak of $77^{\circ} \mathrm{C} \pm 0.5$ was considered to determine $P$. vivax infection.

\section{Statistical analyses}

Correlation between the diagnotics test were evaluated using the Cohen kappa test. Analyses of sensitivity and specificity were performed using the free software package reportROC in RStudio.

\section{Results \\ LAMP analytical sensitivity and specificity}

Using a serial dilution of plasmid for each target, Pfr364-LAMP showed an LOD of 27.3 copies of plas$\mathrm{mid} / \mu \mathrm{L}$ and PfEMP1-LAMP showed an LOD of 28.9 copies of plasmid $/ \mu \mathrm{L}$. For $P$. vivax detection, PvCOX1LAMP showed an LOD of 23.9 copies of plasmid/ $\mu \mathrm{L}$ and the Pvr47-LAMP showed an LOD of 15.6 copies of plasmid $/ \mu \mathrm{L}$ (Table 2 ). In addition, sensitivity analyses were performed using serial dilutions from a 3D7 cultured blood sample for $P$. falciparum to define LOD based on parasites $/ \mu \mathrm{L}$. The results showed an LOD of 3.7 parasites/ $\mu \mathrm{L}$ for Pfr364-LAMP and of 3.3 parasites/ $\mu \mathrm{L}$ for PfEMP1-LAMP. For $P$. vivax, using a pooled samples of blood from infected patients (quantified as parasite $/ \mu \mathrm{L}$ by PCR), the PvCOX1-LAMP showed an LOD of 2.4 parasites/ $\mu \mathrm{L}$ and the Pvr47-LAMP showed an LOD of 3 parasites/ $\mu \mathrm{L}$ (Table 2).

Overall, colorimetric LAMPs with PfEMP1 and Pfr364 targets showed high specificity for detecting $P$. falciparum 3D7 and the corresponding reference samples. These results are shown in Fig. 2. The colorimetric LAMPs designed for $P$. vivax with the COX1 and Pvr47 targets showed a positive reaction with $P$. vivax strain Sal-I, but it also showed a positive reaction with $P$. knowlesi, likely due to the high genomic similarity.

\section{Plasmodium vivax detection using the COX1 and Pvr47 multicopy targets}

The PvCOX1-LAMP displayed the best sensitivity for Plasmodium vivax detection. Using MSC DNA, the PvCOX1-LAMP detected 100\% (21/21) of microscopic samples and $86.7 \%(72 / 83)$ of submicroscopic samples, whereas the Pvr47-LAMP detected only $71.4 \%$ $(15 / 21)$ and $36.1 \%(30 / 83)$ of these samples, respectively (Table 3). Likewise, using BS DNA, the PvCOX1-LAMP detected $81 \%(17 / 21)$ of microscopic samples and $36.1 \%$ (30/83) of submicroscopic samples. The Pvr47-LAMP only detected $52.4 \%(11 / 21)$ and $22.9 \%(19 / 83)$ of these samples, respectively. In the microscopic infection group, only four BS samples produce negative results in PvCOX1-LAMP; two of these samples had parasite densities of 324 and 514 parasites $/ \mu \mathrm{L}$, while the other two showed the lowest parasite density detected by microscopy with 32 parasites $/ \mu \mathrm{L}$.

Overall, 11 of 83 submicroscopic $P$. vivax infections (13.3\%) were negative in PvCOX1-LAMP using sample from both preparation methods (see Additional file 1). Of these samples, one quantified by PCR with 6 parasites/ $\mu \mathrm{L}$ was above the $95 \%$ confidence interval of the LOD (1.8-4.8 parasites $/ \mu \mathrm{L})$, another six samples had parasitaemia values within the interval and four had parasitaemia below this range. Finally, 30 submicroscopic infections were also detected by PvCOX1-LAMP using both types of extracted DNA, whereas 42 were detected only using MSC DNA (Fig. 3a).

Five additional positive samples to $P$. vivax by PvCOX1LAMP were found in the third group of negative samples, by using MSC DNA (Fig. 3a). Upon further examination, these samples were considered to have had lower parasitaemia levels to $P$. vivax, with the Taqman PCR, described by Rougemont et al. [41]. In addition, in Pv47-LAMP, nine samples were positive for $P$. vivax using MSC DNA, five of them were also positive using BS DNA, and one additional sample was positive using BS DNA (Fig. 3b). However, negative results were always obtained for these 10 samples using different real-time PCR methods.

\section{Plasmodium falciparum detection using the EMP1 and Pfr364 multicopy targets}

The sensitivity and specificity of the Pfr 364 and the PfEMP1 targets were similar using all three groups of samples and the PCR as a reference method. Both LAMPs showed a moderate agreement, with Cohen kappa indexes between 0.74-0.82 when using MSC DNA and $0.64-0.57$ when using BS DNA (Table 4).

Both, Pfr364-LAMP and the PfEMP1-LAMP detected all infections positive that were identified by microscopy $(\mathrm{n}=7)$ using DNA from both sample preparation 
Table 2 Limit of detection

\begin{tabular}{|c|c|c|c|}
\hline \multirow{2}{*}{\multicolumn{2}{|c|}{$\begin{array}{l}\text { Using blood samples } \\
\text { PvCOX1-LAMP LOD } 2.4 \text { parasites } / \mu \mathrm{L} 95 \% \mathrm{Cl} 1.8-4.8\end{array}$}} & \multirow{2}{*}{\multicolumn{2}{|c|}{$\begin{array}{l}\text { Using recombinant plasmid by each target } \\
\text { PvCOX1-LAMP LOD } 23.9 \text { copies } / \mu \mathrm{L} 95 \% \mathrm{Cl} 16.1-65.8\end{array}$}} \\
\hline & & & \\
\hline Parasites $/ \mu \mathrm{L}^{\mathrm{a}}$ : & Positive $/ n^{\circ}$ replicates & Plasmid (Copies $/ \mu \mathrm{L}):$ & $\begin{array}{l}\text { Positive/ } \\
\mathrm{n}^{\circ} \\
\text { replicates }\end{array}$ \\
\hline 214.1 & $15 / 15$ & 1684.0 & $15 / 15$ \\
\hline 21.4 & $15 / 15$ & 168.4 & $15 / 15$ \\
\hline 2.1 & $13 / 15$ & 16.8 & $13 / 15$ \\
\hline 1.1 & $9 / 15$ & 8.5 & $7 / 15$ \\
\hline 0.5 & $0 / 15$ & 3.4 & $1 / 15$ \\
\hline \multicolumn{2}{|c|}{ Pvr364-LAMP LOD 3.7 parasites/ $\mu \mathrm{L} 95 \% \mathrm{Cl} 2.8-7.5$} & \multicolumn{2}{|c|}{ Pvr364-LAMP LOD 27.3 copies/ $\mu \mathrm{L} 95 \% \mathrm{Cl} 19.1-133.6$} \\
\hline 3D7 culture (Parasites/ $\mu \mathrm{L})$ : & Positive $/ n^{\circ}$ replicates & Plasmid (Copies $/ \mu \mathrm{L}):$ & $\begin{array}{l}\text { Positive/ } \\
\mathrm{n}^{\circ} \\
\text { replicates }\end{array}$ \\
\hline 314.2 & $15 / 15$ & 1865.5 & $15 / 15$ \\
\hline 31.4 & $15 / 15$ & 186.6 & $15 / 15$ \\
\hline 3.1 & $13 / 15$ & 18.7 & $12 / 15$ \\
\hline 1.6 & $6 / 15$ & 9.3 & $4 / 15$ \\
\hline 0.8 & $0 / 15$ & 1.9 & $0 / 15$ \\
\hline \multicolumn{2}{|c|}{ Pvr47-LAMP LOD 3 parasites/ $\mu \mathrm{L}$ 95\%Cl: 2.1-6.8 } & \multicolumn{2}{|c|}{ Pvr47-LAMP LOD 15.6 copies/ $\mu \mathrm{L}$ 95\%Cl: 11.9-30.5 } \\
\hline Parasites $/ \mu \mathrm{L}^{\mathrm{a}}$ : & Positive $/ \mathrm{n}^{\circ}$ replicates & Plasmid (Copies $/ \mu \mathrm{L}):$ & $\begin{array}{l}\text { Positive/ } \\
\mathrm{n}^{\circ} \\
\text { replicates }\end{array}$ \\
\hline 214.1 & $15 / 15$ & 1631.6 & $15 / 15$ \\
\hline 21.4 & $15 / 15$ & 163.2 & $15 / 15$ \\
\hline 2.1 & $12 / 15$ & 16.3 & $14 / 15$ \\
\hline 1.1 & $5 / 15$ & 8.2 & $9 / 15$ \\
\hline 0.5 & $0 / 15$ & 3.3 & $0 / 15$ \\
\hline \multicolumn{2}{|c|}{ PfEMP1-LAMP LOD 3.3 parasites/ $\mu \mathrm{L}$ 95\%Cl: $2.4-6.7$} & \multicolumn{2}{|c|}{ Pvr47-LAMP LOD 28.9 copies/ $\mu \mathrm{L}$ 95\%Cl: 21.2-86.7 } \\
\hline 3D7 culture (Parasites $/ \mu \mathrm{L})$ : & Positive $/ n^{\circ}$ replicates & Plasmid (Copies $/ \mu \mathrm{L})$ : & $\begin{array}{l}\text { Positive/ } \\
\mathrm{n}^{\circ} \\
\text { replicates }\end{array}$ \\
\hline 314.2 & $15 / 15$ & 2076.0 & $15 / 15$ \\
\hline 31.4 & $15 / 15$ & 207.6 & $15 / 15$ \\
\hline 3.1 & $14 / 15$ & 20.8 & $12 / 15$ \\
\hline 1.6 & $8 / 15$ & 10.4 & $3 / 15$ \\
\hline 0.8 & $1 / 15$ & 2.1 & $0 / 15$ \\
\hline
\end{tabular}

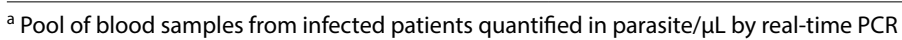

methods. In the submicroscopic group, two of nine $P$. falciparum infections with parasitemia above the 95\% confidence interval of Pfr364-LAMP LOD (2.8-7.5 parasites $/ \mu \mathrm{L}$ ) showed a negative result when tested by Pfr364-LAMP using MSC DNA. One submicroscopic infection with parasitemia above the $95 \%$ confidence interval of PfEMP1-LAMP LOD (2.4-6.7 parasites/ $\mu \mathrm{L})$ showed a negative result when tested by PfEMP-LAMP using MSC DNA. However, both assays exhibited difficulty detecting submicroscopic infections using BS DNA. Moreover, the Pfr364-LAMP detected 6 out of 18 PCR positive samples, whereas PfEMP1-LAMP detected only four samples (Fig. 4). One P. vivax infection detected by PCR with low parasitaemia of 40 parasites $/ \mu \mathrm{L}$ was additionally detected as $P$. falciparum infection by the two LAMPs with both types of extracted DNA. This sample was also positive for $P$. vivax in PvCOX1-LAMP using MSC DNA, and later it 


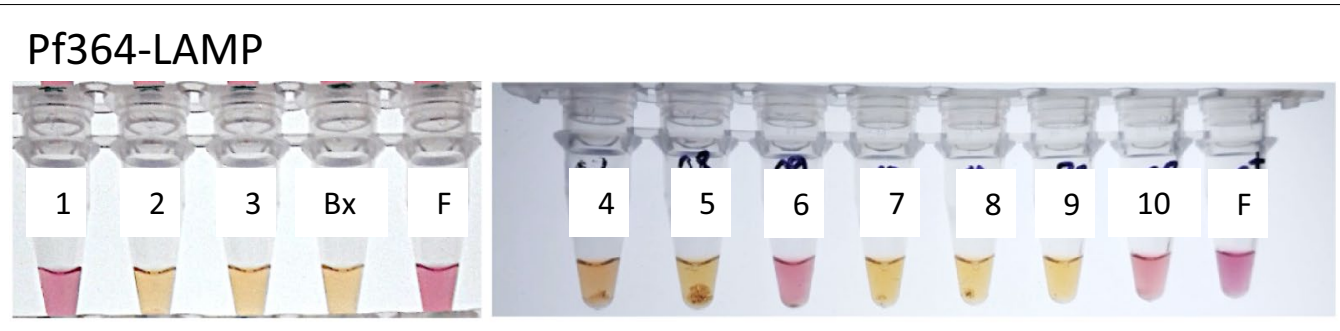

\section{PfEMP1-LAMP}

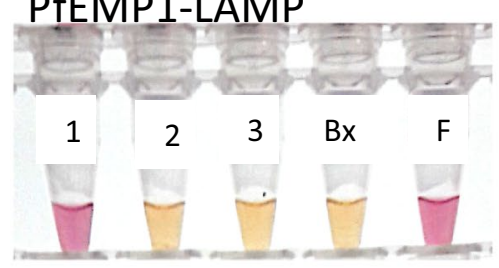

\section{PvCOX1-LAMP}

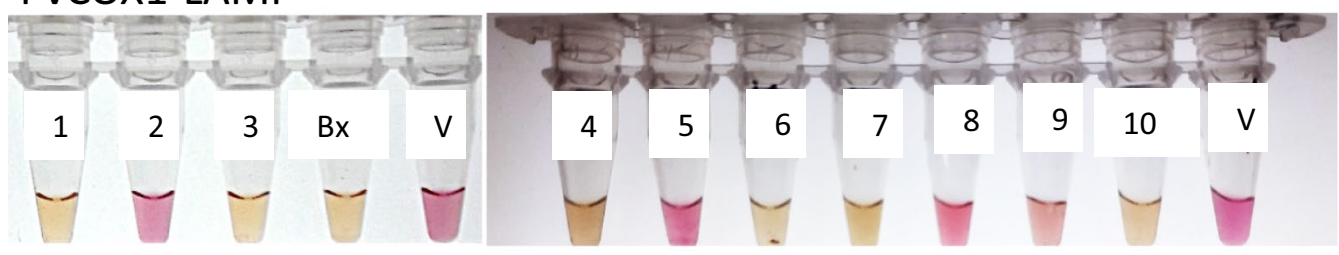

\section{Pvr47-LAMP}

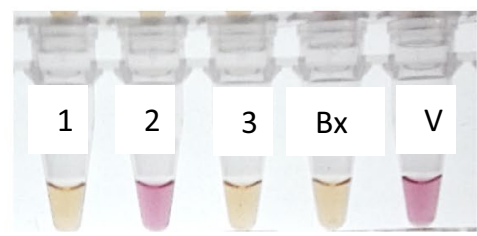

Fig. 2 Specificity of the different colorimetric LAMPs. (1) P. falciparum 3D7; (2) P. vivax Sal-I; (3) P. malariae; (4) P. ovale 200,000 parasites/mL, (5) P. vivax 20,000 parasites/mL, (6) P. falciparum 20,000 parasites/mL, (7) No Plasmodium nucleic acids detected, (8) P. knowlesi 200,000 parasites/mL, (9) P. vivax 10,000 parasites/mL, (10) P. falciparum 10,000 parasites/mL, F) P. falciparum positive control, V) P. vivax positive control, BX) blank control

Table 3 Sensitivity and specificity of Pvr47 and COX1 targets to detect P. vivax

\begin{tabular}{|c|c|c|c|c|c|c|c|c|}
\hline \multirow[b]{3}{*}{$\begin{array}{l}\text { P. vivax infection detected } \\
\text { by microscopy \& PCR }\end{array}$} & \multicolumn{4}{|c|}{ Mini spin column } & \multicolumn{4}{|c|}{ Boil \& Spin } \\
\hline & \multicolumn{2}{|c|}{ Pvr47-LAMP } & \multicolumn{2}{|c|}{ PvCOX1-LAMP } & \multicolumn{2}{|c|}{ Pvr47-LAMP } & \multicolumn{2}{|c|}{ PvCOX1-LAMP } \\
\hline & $71.4 \%$ & $95 \mathrm{Cl} 47.7-87.8 \%$ & $100.00 \%$ & $95 \mathrm{Cl} 80.8-100 \%$ & $52.4 \%$ & $95 \mathrm{Cl} 30.3-73.6 \%$ & $81.0 \%$ & $95 \mathrm{Cl} 57.42-93.71 \%$ \\
\hline$n=21$ & $n=15$ & & $n=21$ & & $n=11$ & & $n=17$ & \\
\hline $\begin{array}{l}\text { P. vivax submicroscopic } \\
\text { infection detected only } \\
\text { by PCR }\end{array}$ & $36.1 \%$ & $95 \mathrm{Cl} 26.1-47.5 \%$ & $86.8 \%$ & $95 \mathrm{Cl} 77.1-92.9 \%$ & $22.9 \%$ & $95 \mathrm{Cl} 14.7-33.7 \%$ & $36.1 \%$ & $95 \mathrm{Cl} 26.1 \%-47.5 \%$ \\
\hline$n=83$ & $n=30$ & & $n=72$ & & $n=19$ & & $n=30$ & \\
\hline $\begin{array}{l}\text { Non P. vivax infection } \\
\text { detected by microscopy } \\
\& P C R\end{array}$ & $95.7 \%$ & 95 Cl 91.7-97.9\% & $97.6 \%$ & $95 \mathrm{Cl} 94.2-99.1 \%$ & $97.1 \%$ & 95 Cl 93.5-98.8\% & $100 \%$ & 95 Cl $97.7-100 \%$ \\
\hline Negatives $=208$ & $n=199$ & & $n=203$ & & $n=202$ & & $n=208$ & \\
\hline Sensitivity $^{a}$ & $43.3 \%$ & 95 Cl: 33.7\%-52.8\% & $89 \%$ & 95 Cl: $83.5 \%-95.3 \%$ & $29 \%$ & 95 Cl: 20.1\%-37.6\% & $45 \%$ & $95 \mathrm{Cl}: 35.6 \%-54.8 \%$ \\
\hline Specificity $^{a}$ & $95.7 \%$ & $95 \mathrm{Cl}$ 92.9-98.4\% & $98 \%$ & $95 \mathrm{Cl}$ 95.5-99.7\% & $97 \%$ & $95 \mathrm{Cl} 94.8-99.4 \%$ & $100 \%$ & $100 \%$ \\
\hline Agreement Cohen's Kappa ${ }^{a}$ & 0.443 & $0.338-0.547$ & 0.883 & $0.827-0.939$ & 0.310 & $0.208-0.412$ & 0.524 & $0.425-0.622$ \\
\hline
\end{tabular}

${ }^{a}$ Reference method: real-time PCR described by Mangold et al. [40] 


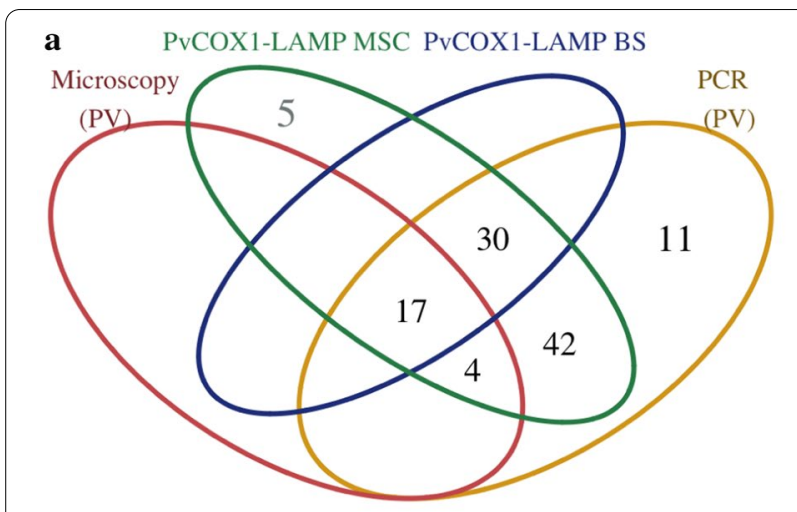

$\mathbf{b}$

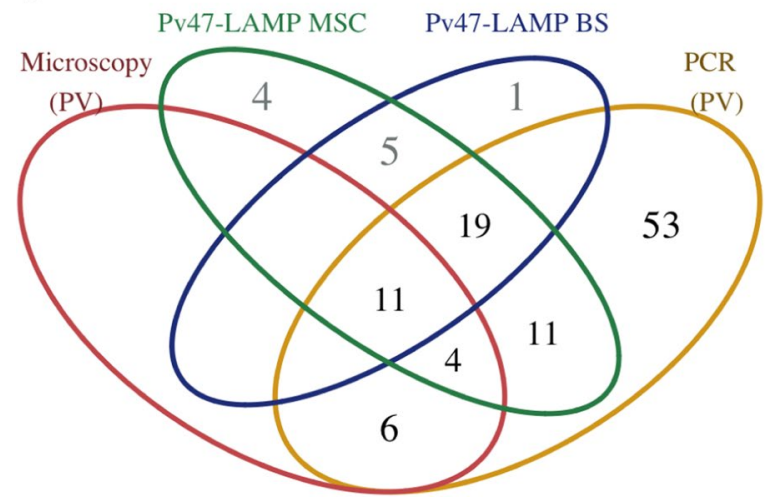

Fig. 3 Venn diagram of the P. vivax detection. a PvCOX1-LAMP comparison with microscopy and PCR. b Pvr47-LAMP comparison with microscopy and PCR. MSC Mini-Spin Column, BS Boil \& Spin

was confirmed by Taqman PCR (as described by Rougemont et al. [41]) to be a mixed sample.

In PfEMP1-LAMP using MSC DNA, two additional P. falciparum were detected. One of these was a P. vivax submicroscopic infection, and the other one was a negative sample.

\section{Plasmodium vivax and $P$. falciparum detection}

Considering the $P$. vivax and $P$. falciparum diagnosis scenario with two individual LAMP assays and the PCR as a reference method, PvCOX1-LAMP and Pfr364-LAMP together showed a sensitivity of $84.5 \%$ compared to the 87.6\% sensitivity of both PvCOX1-LAMP and PfEMP1LAMP together using MSC DNA; the values using BS DNA were $47.3 \%$ and $45.7 \%$, respectively (Table 5 ).

PvCOX1-LAMP and Pfr364-LAMP combined system displayed slightly more specificity than PvCOX1-LAMP and PfEMP1-LAMP combination using MSC DNA, at 97.3\% and $96.7 \%$ respectively (Table 5 ). This slight difference indicates that PfEMP1-LAMP may decrease the specificity of the system when the two individual LAMP assays are used for both $P$. vivax and $P$. falciparum detection.

\section{Discussion}

In Peru, the highest incidence of malaria cases occurs in rural regions where diagnosis by microscopy is still used. However, these areas carry additional challenges, such as the lack of expert microscopy technicians in peripheral health centers and poor maintenance of microscope equipment, which jeopardizes the quality of the results.

In this study, new colorimetric LAMP assays, which were tested with microscopic and submicroscopic samples previously evaluated by real-time PCR. Of the different colorimetric formats available for the visualization of LAMP results, colour change using $\mathrm{pH}$ indicators, such as neutral red, is advantageous compared to dyes such as

Table 4 Sensitivity and specificity of Pfr364 and EMP1 targets to detect Plasmodium falciparum

\begin{tabular}{|c|c|c|c|c|c|c|c|c|}
\hline \multirow[b]{3}{*}{$\begin{array}{l}\text { P. falciparum infection detected by } \\
\text { microscopy \& PCR }\end{array}$} & \multicolumn{4}{|c|}{ Mini spin column } & \multicolumn{4}{|c|}{ Boil \& Spin } \\
\hline & \multicolumn{2}{|c|}{ Pfr364-LAMP } & \multicolumn{2}{|c|}{ PfEMP1-LAMP } & \multicolumn{2}{|c|}{ Pfr364-LAMP } & \multicolumn{2}{|c|}{ PfEMP1-LAMP } \\
\hline & $100.0 \%$ & $95 \mathrm{Cl} 56.1-100 \%$ & $100.0 \%$ & 95 Cl 56.1-100\% & $100.0 \%$ & 95 Cl 56.1-100\% & $100.0 \%$ & 95 Cl 56.1-100\% \\
\hline$n=7$ & $n=7$ & & $n=7$ & & $n=7$ & & $n=7$ & \\
\hline $\begin{array}{l}\text { P. falciparum submicroscopic infec- } \\
\text { tion detected only by PCR }\end{array}$ & $50.0 \%$ & $95 \mathrm{Cl} 29.0-71 \%$ & $72.2 \%$ & $95 \mathrm{Cl} 46.4-89.3 \%$ & $33.3 \%$ & $95 \mathrm{Cl}$ 14.4-58.9\% & $22.2 \%$ & $95 \mathrm{Cl} 7.4-48.1 \%$ \\
\hline$n=18$ & $n=9$ & & $n=13$ & & $n=6$ & & $n=4$ & \\
\hline $\begin{array}{l}\text { Non } P \text {. falciparum infection detected } \\
\text { by microscopy \& PCR }\end{array}$ & $99.7 \%$ & 95 Cl 97.8-100\% & $99.0 \%$ & 95 Cl 96.8-99.7\% & $99.7 \%$ & 95 Cl 97.8-100\% & $99.7 \%$ & 95 Cl 97.8-100\% \\
\hline$n=287$ & $n=286$ & & $n=284$ & & $n=286$ & & $n=286$ & \\
\hline Sensitivity ${ }^{a}$ & $64.0 \%$ & $95 \mathrm{Cl} 45.2-82.8 \%$ & $80.0 \%$ & 95 Cl 64.3-95.7\% & $52.0 \%$ & $95 \mathrm{Cl} 32.4-71.6 \%$ & $44.0 \%$ & $95 \mathrm{Cl} 24.5-63.5 \%$ \\
\hline Specificity $^{a}$ & $99.7 \%$ & $95 \mathrm{Cl} 99-100 \%$ & $99.0 \%$ & 95 Cl 97.8-100\% & $99.7 \%$ & 95Cl99-100\% & $99.7 \%$ & $95 \mathrm{Cl} 99-100 \%$ \\
\hline Agreement Cohen's Kappa ${ }^{\mathrm{a}}$ & 0.745 & $0.595-0.896$ & 0.820 & $0.698-0.941$ & 0.646 & $0.470-0.823$ & 0.572 & $0.381-0.764$ \\
\hline
\end{tabular}

${ }^{a}$ Reference method: real-time PCR described by Mangold et al. [40] 


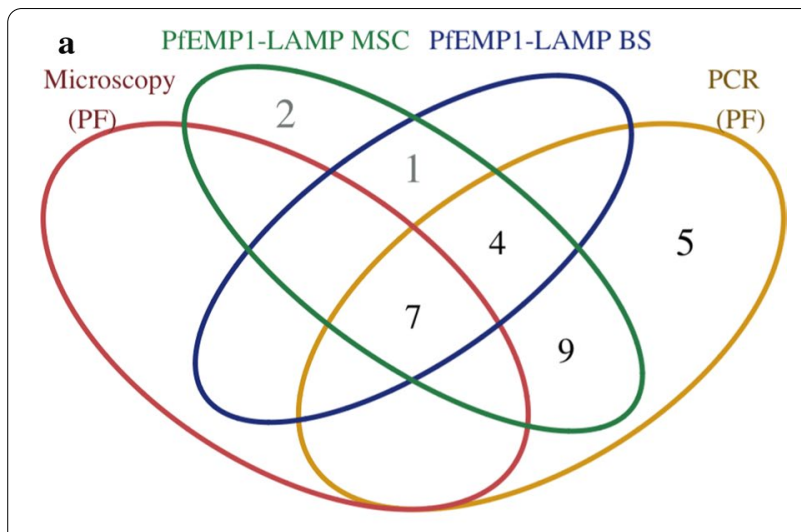

b

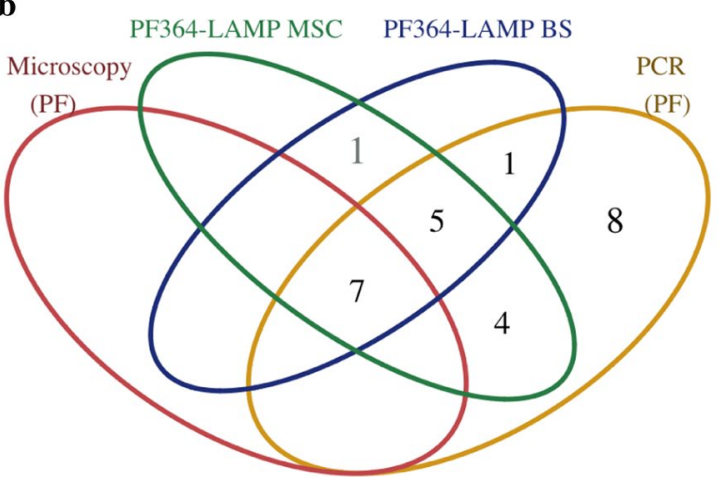

Fig. 4 Venn diagram of the $P$. falciparum detection by diagnostic method. a PfEMP1-LAMP comparison with microscopy and PCR. b Pfr364-LAMP comparison with microscopy and PCR. MSC Mini-Spin Column, BS Boil \& Spin malachite green, which can vary in colour intensity and bias the visualization to yield unsatisfactory results [42].

In laboratory conditions, the colorimetric LAMPs showed an LOD between 2.4 and 3.7 parasites/ $\mu \mathrm{L}$. This detection level is comparable with other LAMP studies for malaria diagnosis, in which the sensitivity has varied according to the target employed. Several studies have reported LODs of $10-125$ parasites/ $\mu \mathrm{L}$ using genus-specific and species-specific tests with targets such as $18 \mathrm{~S}$ rRNA target, alpha-tubulin, and r64 repeat sequences [43-45]. A lower LOD (between 1.4 and 5 parasites $/ \mu \mathrm{L}$ ) was reached using the species-specific test for $P$. vivax and $P$. falciparum with a multicopy mitochondrial target [20, 23, 46].

Four $P$. vivax microscopic infections with parasitaemia higher than the LOD determined for PvCOX1-LAMP were negative when analysed by BS DNA. These samples were four out of the six samples with the lowest parasitaemia in the microscopic infection group, and the negative result could have been affected by inhibitors that the sample preparation method could not remove. Likewise, one $P$. vivax submicroscopic infection with parasitaemia above the 95\% confidence interval of the PvCOX1LAMP LOD (1.8-4.8 parasites/ $\mu \mathrm{L})$ showed a negative result when tested using PvCOX1-LAMP paired with MSC DNA. Similarly, two of nine P. falciparum submicroscopic infections with parasitaemia above the 95\% confidence interval of Pfr364-LAMP LOD (2.8-7.5 parasites $/ \mu \mathrm{L}$ ) showed a negative result when tested by Pfr364LAMP paired with MSC DNA. These negative results significantly increased when BS DNA was used for this submicroscopic group. In fact, the false negatives with a parasitaemia level close to the LOD could be explained

Table 5 Sensitivity and specificity for $P$. vivax and $P$. falciparum detection

\begin{tabular}{|c|c|c|c|c|c|c|c|c|}
\hline \multirow[b]{3}{*}{$\begin{array}{l}\text { P. vivax and } P \text {. falciparum infection } \\
\text { detected by microscopy \& PCR }\end{array}$} & \multicolumn{4}{|c|}{ Mini Spin Column } & \multicolumn{4}{|c|}{ Boil \& Spin } \\
\hline & \multicolumn{2}{|c|}{$\begin{array}{l}\text { PvCOX1-LAMP \& Pfr364- } \\
\text { LAMP }\end{array}$} & \multicolumn{2}{|c|}{$\begin{array}{l}\text { PvCOX1-LAMP \& } \\
\text { PfEMP1-LAMP }\end{array}$} & \multicolumn{2}{|c|}{$\begin{array}{l}\text { PvCOX1-LAMP \& Pfr364- } \\
\text { LAMP }\end{array}$} & \multicolumn{2}{|c|}{$\begin{array}{l}\text { PvCOX1-LAMP \& } \\
\text { PfEMP1-LAMP }\end{array}$} \\
\hline & $100.0 \%$ & $95 \mathrm{Cl} 85-100 \%$ & $100.0 \%$ & $95 \mathrm{Cl} 85-100 \%$ & $85.7 \%$ & $95 \mathrm{Cl} 66.4-95.3 \%$ & $85.7 \%$ & $95 \mathrm{Cl} 66.4-95.3 \%$ \\
\hline$n=28$ & $n=28$ & & $n=28$ & & $n=24$ & & $n=24$ & \\
\hline $\begin{array}{l}\text { P. vivax and } P \text {. falciparum submicro- } \\
\text { scopic infection detected only } \\
\text { by PCR }\end{array}$ & $80.2 \%$ & $95 \mathrm{Cl} 70.8-87.2 \%$ & $84.2 \%$ & $95 \mathrm{Cl} 75.3-90.4 \%$ & $36.6 \%$ & $95 \mathrm{Cl} 27.4-46.86 \%$ & $34.7 \%$ & 95 Cl 25.64-44.9\% \\
\hline$n=101$ & $\mathrm{n}=81$ & & $\mathrm{n}=85$ & & $n=37$ & & $n=35$ & \\
\hline $\begin{array}{l}\text { Non } P \text {. vivax and } P \text {. falciparum infec- } \\
\text { tion detected by Microscopy } \\
\& P C R\end{array}$ & $97.3 \%$ & 95 Cl 93.4-99\% & $96.7 \%$ & 95 Cl 92.7-98.7\% & $100.0 \%$ & 95 Cl 97.4-100\% & $100.0 \%$ & 95 Cl 97.4-100\% \\
\hline$n=183$ & $n=178$ & & $n=177$ & & $n=183$ & & $n=183$ & \\
\hline Sensitivity ${ }^{a}$ & $84.5 \%$ & $95 \mathrm{Cl} 78.3-90.7 \%$ & $87.6 \%$ & $95 \mathrm{Cl}$ 81.9-93.3\% & $47.3 \%$ & $95 \mathrm{Cl} 38.7-55.9 \%$ & $45.7 \%$ & $95 \mathrm{Cl} 37.1-54.3 \%$ \\
\hline Specificity ${ }^{a}$ & $97.3 \%$ & $95 \mathrm{Cl} 94.9-99.6 \%$ & $96.7 \%$ & 95 Cl 94.1-99.3\% & $100.0 \%$ & $95 \mathrm{Cl} 100-100 \%$ & $100.0 \%$ & $95 \mathrm{Cl} 100-100 \%$ \\
\hline Agreement Cohen's Kappa $^{a}$ & 0.832 & $0.769-0.895$ & 0.853 & $0.794-0.912$ & 0.513 & $0.423-0.602$ & 0.497 & $0.407-0.587$ \\
\hline
\end{tabular}

${ }^{a}$ Reference method: real-time PCR described by Mangold et al.[40] 
by the low DNA quality, which was lower using the Boil \& Spin method due to enzyme inhibitors.

The designed LAMP assays have proven to be highly specific using samples of different types of Plasmodium. Only the COX1 target showed reactivity for $P$. vivax and $P$. knowlesi, most likely because the two species are genetically related; however, this disadvantage only represents a problem in Asian countries where P. knowlesi is more predominant [47]. Despite that the Pvr47 target demonstrating high specificity and sensitivity in detecting $P$. vivax by real-time PCR [37], the Pvr47-LAMP designed in this study showed lower $P$. vivax detection compared to the PvCOX1-LAMP, using either MSC or BS DNA. Thus, future evaluation is necessary to determine a possible cause, such as a mismatched primer in this multicopy target.

Comparing the sample preparation methods, the use of Boil \& Spin method was simple, fast and did not require much experience, in contrast the commercial mini spin column kit required some experience in handling laboratory materials and special storage conditions. In addition, the reagents were less expensive using the formed method: \$ 0.03 USD per extraction for Boil \& Spin and $\$ 2.70$ USD per extraction for the mini spin column kit. However, the performance of the formed decreased when the amplification target was present in low quantities and due to the presence of enzyme inhibitors that could not be eliminated.

Overall, the results with the malaria microscopic infections group indicate that LAMP assays whit MSC DNA can be used instead of the microscopy diagnosis, because all the microscopic samples tested gave a positive reaction with the respective LAMP assay (PvCOX1-LAMP for $P$. vivax and PfEMP1-LAMP or Pfr364-LAMP for $P$. falciparum). Similarly, assays using BS DNA also showed high performance, with only four such samples testing negative for $P$. vivax. Nonetheless, a future study with a greater number is needed to determine if the Boil \& Spin method can be used when diagnostic by microscopy cannot be performed with the good requirements of quality.

The PvCOX1-LAMP detected five samples positive for $P$. vivax that were negative in the real-time PCR described by Mangold et al. [40]. Indeed, these were all confirmed to be $P$. vivax infections using the Taqman PCR described by Rougemont et al. [41]; they had very low parasite loads at 5 parasites $/ \mu \mathrm{L}$. This discrepancy was probably due to stochastic amplification occurring at low parasite densities.

As noted above, both Pfr364-LAMP and PfEMP1LAMP detected all $P$. falciparum microscopic infections with both types of DNA extracted. However, they both showed the same difficulties in detecting submicroscopic infections below 10 parasites/ $\mu \mathrm{L}$ (see Fig. 4 and
Additional file 1). Unfortunately, the number of samples evaluated for $P$. falciparum was very small, which prevented from defining the best test for a suitable routine evaluation of this species. However, based on the results of species identification, the more specific assay for detecting P. falciparum was Pfr364-LAMP.

In the context of malaria diagnosis in the field, the PMC promotes the training of microscopists to achieve quality and prompt diagnosis to give specific treatment. However, the species-specific diagnosis of submicroscopic infections remains the main challenge. The LAMP techniques would greatly complement microscopy diagnostic by detecting an essential group of submicroscopic infections with high specificity, as demonstrated by the results of this study.

These newly developed colorimetric LAMP assays have significant advantages, such as the low cost and a straightforward interpretation of results based on the naked-eye visual inspection. These assays should be further evaluated in the field and at POC to determine field implementation logistics and healthcare worker training requirements. As mentioned above, the use of Boil \& Spin or further simplified DNA methods would improve the malaria diagnosis at POC in settings with poor-quality microscopic diagnostic conditions. Moreover, an additional investment to use mini spin column kits would allow for a better diagnosis by detecting many submicroscopic infections.

\section{Conclusion}

The simultaneous use of COX1 and Pfr364 multicopy target in colorimetric LAMP for both $P$. vivax and $P$. falciparum detection improved diagnosis detecting $37(36.63 \%)$ and $81(80.20 \%)$ submicroscopic infections using a simple method of sample preparation (Boil \& Spin) or a mini column spin kit, respectively.

\section{Abbreviations}

BLAST: Basic Local Alignment Tool; COX1: Cytochrome oxidase I; DNA: Desoxyribonucleic acid; EDTA: Ethylene diamine tetra-acetic acid; EMP1: Erythrocyte membrane protein 1; HRP2: Histidine-rich protein 2; LAMP: Loop-mediated Isothermal amplification; LOD: Limit of detection; MG-LAMP: Malachite green colorimetric LAMP; NIH: National Institute of Health; NCBI: National Center for Biotechnology Information; PCR: Polymerase chain reaction; PMC: Plan Malaria Cero; POC: Point of care; RDTs: Rapid diagnostics tests; SDS: Sodium dodecyl sulfate; TEN buffer: Tris-EDTA Sodium chloride buffer; 18S rRNA: Ribosomal sub-unit small 18 S RNA.

\section{Supplementary Information}

The online version contains supplementary material available at https://doi. org/10.1186/s12936-021-03753-8.

Additional file 1. Malaria Diagnosis data. 


\section{Acknowledgements}

We would like to thank IMTAvH malaria group for providing all the clinical samples. Our thanks to the ITM Antwerp and CDC for providing DNA control of $P$. falciparum culture and blood samples DNA extracted from patient materials that served as Plasmodium falciparum, Plasmodium vivax, Plasmodium ovale and Plasmodium malariae positive

\section{Authors' contributions}

ON designed the study, performed all data analysis, coordinated with collaborators and write this manuscript. JM designed and optimized the PVCOX1LAMP and PFEMP1-LAMP. ALRR designed and optimized the PVr47-LAMP and Pfr364-LAMP. SB cloned the targets and assessed the limits of detection. AR-U was involved in including the reference material, external collaborator and adviser of study. DG was involved in including the reference material, advised on the designed study. All authors read and approved the final manuscript.

\section{Funding}

The study was supported by Project Belgian Development Cooperation (DGD) through the collaborative project Framework Agreement 4 (FA4) between the IMTAvH and the Institute of Tropical Medicine of Antwerp. Oscar Nolasco is supported by Project "Translational Research Development for Endemic Infectious Diseases of Amazonia - FOGARTY". Grant number: 2D43TW007120-11A1, and The COBIAN scholarship from Facultad de Ciencias y Filosofía, Universidada Peruana Cayetano Heredia.

\section{Data availability}

The datasets generated during and/or analysed during the current study are available from the corresponding author on reasonable request.

\section{Declarations}

\section{Ethics approval and consent to participate}

Ethical approval was obtained from the corresponding Ethical Review board from Universidad Peruana Cayetano Heredia (SIDISI Project: 201296 and Constancy letter: E070-14-20).

\section{Consent for publication}

All authors have reviewed the manuscript and consented for publication.

\section{Competing interests}

The authors declare that they have no competing interests.

\section{Author details}

${ }^{1}$ Instituto de Medicina Tropical "Alexander von Humboldt" Universidad Peruana Cayetano Heredia, Lima, Peru. ${ }^{2}$ Unidad de Posgrado de la Facultad de Ciencias Biológicas Universidad Nacional Mayor de San Marcos, Lima, Peru. ${ }^{3}$ Laboratorios de Investigación Y Desarrollo, Facultad de Ciencias Y Filosofía, Universidad Peruana Cayetano Heredia, Lima, Peru. ${ }^{4}$ Department of Biomedical Sciences, Institute of Tropical Medicine, Antwerp, Belgium. ${ }^{5}$ Departamento de Ciencias Celulares Y Moleculares, Facultad de Ciencias Y Filosofía, Universidad Peruana Cayetano Heredia, Lima, Peru.

Received: 21 January 2021 Accepted: 7 May 2021

Published online: 19 May 2021

\section{References}

1. WHO. World malaria report 2020. Geneva: World Health Organization; 2020.

2. Centro Nacional de Epidemiología, Prevención y Control de Enfermedades. Situación de la malaria en el Perú. Boletin Epidemiológico 02-2021. https://www.dge.gob.pe/epipublic/uploads/boletin/boletin_20212.pdf. Accessed 17 Mar 2021.

3. Rovira-Vallbona E, Contreras-Mancilla JJ, Ramirez R, Guzman-Guzman M, Carrasco-Escobar G, Llanos-Cuentas A, et al. Predominance of asymptomatic and sub-microscopic infections characterizes the Plasmodium gametocyte reservoir in the Peruvian Amazon. PLoS Negl Trop Dis. 2017;11:e0005674.
4. Okell LC, Ghani AC, Lyons E, Drakeley CJ. Submicroscopic infection in Plasmodium falciparum-endemic populations: a systematic review and meta-analysis. J Infect Dis. 2009;200:1509-17.

5. Ministerio de Salud del Perú. Norma técnica para la atención de la malaria y malaria severa en el Perú. NTS Nro. 054-MINSA/DGSP-V.01, modificada en Febrero 2015. MINSA; 2015. http://bvs.minsa.gob.pe/local/MINSA/ 4373.pdf. Accessed 17 Mar 2021.

6. Hänscheid T. Diagnosis of malaria: a review of alternatives to conventional microscopy. Clin Lab Haematol. 1999:21:235-45.

7. Kilian AH, Metzger WG, Mutschelknauss EJ, Kabagambe G, Langi P, Korte $R$, et al. Reliability of malaria microscopy in epidemiological studies: results of quality control. Trop Med Int Health. 2000;5:3-8.

8. Mukkala AN, Kwan J, Lau R, Harris D, Kain D, Boggild AK. An update on malaria rapid diagnostic tests. Curr Infect Dis Rep. 2018;20:49.

9. Jang JW, Cho CH, Han ET, An SS, Lim CS. pLDH level of clinically isolated Plasmodium vivax and detection limit of pLDH based malaria rapid diagnostic test. Malar J. 2013;12:181.

10. Maltha J, Gamboa D, Bendezu J, Sanchez L, Cnops L, Gillet P, et al. Rapid diagnostic tests for malaria diagnosis in the Peruvian Amazon: impact of pfhrp2 gene deletions and cross-reactions. PLoS ONE. 2012;7:e43094.

11. Gamboa D, Ho MF, Bendezu J, Torres K, Chiodini PL, Barnwell JW, et al. A large proportion of $P$. falciparum isolates in the Amazon region of Peru lack pfhrp2 and pfhrp3: implications for malaria rapid diagnostic tests. PLOS ONE. 2010;5:e8091.

12. Rosas-Aguirre A, Speybroeck N, Llanos-Cuentas A, Rosanas-Urgell A Carrasco-Escobar G, Rodriguez $\mathrm{H}$, et al. Hotspots of malaria transmission in the Peruvian Amazon: rapid assessment through a parasitological and serological survey. PLoS ONE. 2015;10:e0137458.

13. Rosas-Aguirre A, Guzman-Guzman M, Gamboa D, Chuquiyauri R, Ramirez $\mathrm{R}$, Manrique $\mathrm{P}$, et al. Micro-heterogeneity of malaria transmission in the Peruvian Amazon: a baseline assessment underlying a population-based cohort study. Malar J. 2017;16:312.

14. Rosas-Aguirre A, Guzman-Guzman M, Chuquiyauri R, Moreno M, Manrique $\mathrm{P}$, Ramirez $\mathrm{R}$, et al. Temporal and micro-spatial heterogeneity in transmission dynamics of co-endemic Plasmodium vivax and Plasmodium falciparum in two rural cohort populations in the Peruvian Amazon. J Infect Dis. 2020;223:1466-77.

15. Carrasco-Escobar G, Miranda-Alban J, Fernandez-Minope C, Brouwer KC, Torres K, Calderon M, et al. High prevalence of very-low Plasmodium falciparum and Plasmodium vivax parasitaemia carriers in the Peruvian Amazon: insights into local and occupational mobility-related transmission. Malar J. 2017;16:415

16. Mercereau-Puijalon O, Barale J, Bischoff E. Three multigene families in Plasmodium parasites: facts and questions. Int J Parasitol. 2002;32:1323-44

17. Notomi T, Okayama H, Masubuchi H, Yonekawa T, Watanabe K, Amino N, et al. Loop-mediated isothermal amplification of DNA. Nucleic Acids Res. 2000;28:E63.

18. Goto M, Honda E, Ogura A, Nomoto A, Hanaki K. Colorimetric detection of loop-mediated isothermal amplification reaction by using hydroxy naphthol blue. Biotechniques. 2009;3:167-72.

19. Tanner NA, Zhang Y, Evans TC Jr. Visual detection of isothermal nucleic acid amplification using pH-sensitive dyes. Biotechniques. 2015:58:59-68.

20. Polley SD, Mori Y, Watson J, Perkins MD, Gonzalez IJ, Notomi T, et al. Mitochondrial DNA targets increase sensitivity of malaria detection using loop-mediated isothermal amplification. J Clin Microbiol. 2010;48:2866-71.

21. Hopkins H, González I, Polley S, Angutoko P, Ategeka J, Asiimwe C, et al. Highly sensitive detection of malaria parasitemia in a malaria-endemic setting: performance of a new loop-mediated isothermal amplification kit in a remote clinic in Uganda. J Infect Dis. 2013;208:645-52.

22. González IJ, Polley S, Hopkins H, Sutherland C, Mori Y, Perkins M, Bell D. Molecular diagnosis for screening and elimination of malaria: performance of the first commercially-available malaria LAMP test. Malar J. 2012;15:11.

23. Aydin-Schmidt B, Xu W, González I, Polley S, Bell D, Shakely D, et al. Loop mediated isothermal amplification (LAMP) accurately detects malaria DNA from filter paper blood samples of low density parasitaemias. PLoS ONE. 2014;9:e103905.

24. Britton S, Cheng Q, McCarthy JS. Novel molecular diagnostic tools for malaria elimination: a review of options from the point of view of 
high-throughput and applicability in resource limited settings. Malar J. 2016;15:88.

25. Modak SS, Barber CA, Geva E, Abrams WR, Malamud D, Ongagna YS Rapid point-of-care isothermal amplification assay for the detection of malaria without nucleic acid purification. Infect Dis (Auckl). 2016;9:1-9.

26. Lucchi NW, Gaye M, Diallo MA, Goldman IF, Ljolje D, Deme AB, et al. Evaluation of the illumigene malaria LAMP: a robust molecular diagnostic tool for malaria parasites. Sci Rep. 2016;6:36808.

27. Lucchi NW, Ljolje D, Silva-Flannery L, Udhayakumar V. Use of malachite green-loop mediated isothermal amplification for detection of Plasmodium spp. parasites. PLoS ONE. 2016;11:e0151437.

28. Imai K, Tarumoto N, Misawa K, Runtuwene LR, Sakai J, Hayashida K, et al. A novel diagnostic method for malaria using loop-mediated isothermal amplification (LAMP) and MinION ${ }^{\top M}$ nanopore sequencer. BMC Infect Dis. 2017;17:621.

29. Mohon AN, Getie S, Jahan N, Alam MS, Pillai DR. Ultrasensitive loop mediated isothermal amplification (US-LAMP) to detect malaria for elimination. Malar J. 2019:18:350.

30. Kudyba H, Louzada J, Ljolje D, Kudyba K, Muralidharan V, Oliveira-Ferreira J, et al. Field evaluation of malaria malachite green loop-mediated isothermal amplification in health posts in Roraima state, Brazil. Malar J. 2019;18:98

31. Selvarajah D, Naing C, Htet NH, Mak JW. Loop-mediated isothermal amplification (LAMP) test for diagnosis of uncomplicated malaria in endemic areas: a meta-analysis of diagnostic test accuracy. Malar J. 2020;19:211.

32. Barazorda KA, Salas CJ, Bishop DK, Lucchi N, Valdivia HO. Comparison of realtime and malachite-green based loop-mediated isothermal amplification assays for the detection of Plasmodium vivax and P. falciparum. PLOS ONE. 2020;6:e0234263.

33. Serra-Casas E, Manrique P, Ding X, Carrasco-Escobar G, Alava F, Gave A, et al. Loop-mediated isothermal DNA amplification for asymptomatic malaria detection in challenging field settings: technical performance and pilot implementation in the Peruvian Amazon. PLOS ONE. 2017:12:e0185742.

34. Nolasco O, Infante B, Contreras-Mancilla, Incardona S, Ding XC, Gamboa $D$, et al. Diagnosis of Plasmodium vivax by loop-mediated isothermal amplification in febrile patient samples from Loreto, Perú. Am J Trop Med Hyg. 2020;4:1549-52.

35. Hofmann N, Mwingira F, Shekalaghe S, Robinson LJ, Mueller I, Felger I. Ultra-sensitive detection of Plasmodium falciparum by amplification of multi-copy subtelomeric targets. PLoS Med. 2015;12:e1001788.

36. Gruenberg M, Moniz CA, Hofmann NE, Wampfler R, Koepfli C, Mueller I, et al. Plasmodium vivax molecular diagnostics in community surveys: pitfalls and solutions. Malar J. 2018;17:55.
37. Demas A, Oberstaller J, DeBarry J, Lucchi NW, Srinivasamoorthy G, Sumari $D$, et al. Applied genomics: data mining reveals species-specific malaria diagnostic targets more sensitive than 18S rRNA. J Clin Microbiol. 2011:49:2411-8.

38. Amaral LC, Robortella DR, Guimarães LFF, Limongi JE, Fontes CJF, Pereira $\mathrm{DB}$, et al. Ribosomal and non-ribosomal PCR targets for the detection of low-density and mixed malaria infections. Malar J. 2019;18:154.

39. Grabias B, Essuman E, Quakyi IA, Kumar S. Sensitive real-time PCR detection of Plasmodium falciparum parasites in whole blood by erythrocyte membrane protein 1 gene amplification. Malar J. 2019;18:116.

40. Mangold KA, Manson RU, Koay ESC, Stephens L, Regner M, Thomson RB, et al. Real-time PCR for detection and identification of Plasmodium spp. J Clin Microbiol. 2005;43:2435-40.

41. Rougemont M, Van Saanen M, Sahli R, Hinrikson HP, Bille J, Jaton K. Detection of four Plasmodium species in blood from humans by $18 \mathrm{~S}$ rRNA gene subunit-based and species-specific real-time PCR assays. J Clin Microbiol. 2004;42:5636-43.

42. Choopara I, Arunrut N, Kiatpathomchai W, Dean D, Somboonna N. Rapid and visual Chlamydia trachomatis detection using loop-mediated isothermal amplification and hydroxynaphthol blue. Lett Appl Microbiol. 2017;64:51-6.

43. Han E-T, Watanabe R, Sattabongkot J, Khuntirat B, Sirichaisinthop J, Iriko $H$, et al. Detection of four Plasmodium species by genus-and speciesspecific loop-mediated isothermal amplification for clinical diagnosis. J Clin Microbiol. 2007;45:2521-8.

44. Patel J, Oberstaller J, Xayavong M, Narayanan J, DeBarry J, Srinivasamoorthy $\mathrm{G}$, et al. Real-time loop-mediated isothermal amplification (RealAmp) for the species-specific identification of Plasmodium vivax. PLoS ONE. 2013:8:e54986.

45. Dinzouna-Boutamba S, Yang H, Joo S, Jeong S, Na B, Inoue N, et al. The development of loop-mediated isothermal amplification targeting alpha-tubulin DNA for the rapid detection of Plasmodium vivax. Malar J. 2014;13:248.

46. Britton S, Cheng Q, Grigg M, Poole C, Pasay C, William T, et al. Sensitive detection of Plasmodium vivax using a high-throughput, colourimetric loop mediated isothermal amplification (HtLAMP) platform: a potential novel tool for malaria elimination. PLoS NegI Trop Dis. 2016;10:e0004443.

47. Moyes CL, Henry AJ, Golding N, Huang Z, Singh B, Baird JK, et al. Defining the geographical range of the Plasmodium knowlesi reservoir. PLoS Negl Trop Dis. 2014;8:e2780.

\section{Publisher's Note}

Springer Nature remains neutral with regard to jurisdictional claims in published maps and institutional affiliations.
Ready to submit your research? Choose BMC and benefit from:

- fast, convenient online submission

- thorough peer review by experienced researchers in your field

- rapid publication on acceptance

- support for research data, including large and complex data types

- gold Open Access which fosters wider collaboration and increased citations

- maximum visibility for your research: over $100 \mathrm{M}$ website views per year

At BMC, research is always in progress.

Learn more biomedcentral.com/submissions 